\title{
A PESQUISA EM ENFERMAGEM: NOTAS DE ORDEM HISTÓRICA E METODOLÓGICA
}

\author{
Magali Roseira Boemer ${ }^{*}$ \\ Semiramis Melani de Melo Rocha**
}

\begin{abstract}
Resumo: $O$ artigo se propõe a algumas considerações sobre a pesquisa em enfermagem no que se refere ao referencial teórico e caminhos metodológicos. Com esse intuito, seus autores resgatam o momento em que a enfermagem passa por um redirecionamento do método clássico de investigação para novas propostas metodológicas, contemplando outros objetos de estudo, possibilitando, assim, novos horizontes epistemológicos para a geração do conhecimento. Discutem questões relacionadas à coerência interna da pesquisa qualitativa, à observância de seus pressupostos filosóficos, ressaltando a importância da produção de conhecimentos que respondam às indagações do assistir e do cuidar em enfermagem.
\end{abstract}

Palavras chave: Pesquisa em enfermagem; pesquisa qualitativa; cuidados em enfermagem; enfoques teórico-metodológicos; epistemologia.

* Prof. Associado Aposentado da Escola de Enfermagem de Ribeirão Preto da USP.

** Prof. Titular da Escola de Enfermagem de Ribeirão Preto da USP. 


\section{INTRODUÇÃO}

Neste artigo nos propomos tecer considerações sobre a pesquisa em enfermagem no que se refere ao seu referencial teórico e caminhos metodológicos. Para tanto, faremos um breve histórico de seu desenvolvimento neste século, pontuando suas principais influências epistemológicas e sua trajetória, a partir de sua institucionalização na América do Norte até o momento atual no Brasil.Essas considerações referem-se à busca de metodologias qualitativas que surgem a partir da década de 70 , busca essa aparentemente relacionada a um cotidiano vivencial dos enfermeiros, do qual emergem objetos de estudo permeados por sentimentos como empatia, simpatia, sofrimento, solidariedade na dor, liberdade. Outros determinantes dessa busca poderiam estar interligados a uma prática profissional na qual predomina a hegemonia do profissional médico, implicando num processo de trabalho em saúde cujas relações e tendências se mostram aos enfermeiros de forma conflitiva, contraditória e carente de explicitações.

Há de se mencionar ainda que o enfermeiro atua em uma sociedade caracterizada por profundas desigualdades sociais, gerando um processo saúde-doença onde estão presentes desequilibrios relacionados às condições de existência.

\section{HISTÓRICO}

CUSHING(1994), revisando a literatura, observa que a enfermagem, encorajada pelas enfermeiras educadoras norte americanas, procurou pelo modelo das ciências biomédicas e físicas para criar uma ciência de enfermagem. Na década de vinte, o estudo de caso foi introduzido com vistas a sistematizar o conhecimento para o ensino de enfermagem, sendo logo reconhecida sua insuficiência enquanto referencial teórico que desse suporte à profissão emergente. Essas educadoras, neste momento, atentam para a necessidade da pesquisa em enfermagem. 
O primeiro corpo de conhecimentos denominado técnicas de enfermagem instrumentalizou a profissão e consistiu na normatização de procedimentos, com base em noções tayloristas, conforme referem ALMEIDA \& ROCHA(1986).

O referencial metodológico das ciências naturais vai prover a fundamentação da investigação em enfermagem até os anos 60 , quando este modelo, por possibilitar somente uma abordagem quantitativa, começa a se mostrar às enfermeiras norteamericanas como prescritivo, rigido e pertinente às mensurações. Para essa percepção de restrição, da não pertinência desse referencial para determinados objetos de investigação foi relevante a influência da sociologia e teoria social.

Segundo RAY(1985), as limitações da metodologia clássica de investigação vinham conduzindo para uma visão parcial do processo dinâmico das experiências vividas num contexto histórico e cultural. A dificuldade em reunir essas partes levou os pesquisadores a examinar a importância de métodos qualitativos. Essa autora lembra ainda que a enfermagem não é a única área que está engajada num processo de reexame, dado que a ciência, em geral, tem um novo ponto na história. A idéia de um universo estático é agora incompatível com o novo conceito de mundo enquanto um processo dinâmico.

Para SAUER(1985), o paradigma das ciências humanas é bastante pertinente à área de enfermagem porque possibilita metodologias que podem levar a formas de compreensão da experiência humana. OMERY(1983) lembra que a insuficiêncià do método cientifico tradicional levou muitos pesquisadores da área de enfermagem a buscar metodologias alternativas de pesquisa na vertente qualitativa.

Assim, o campo de investigação em enfermagem passa por um redirecionamento através do qual se abrem outras possibilidades de investigação e as enfermeiras ousaram 
recorrer a novas metodologias com o objetivo de dar continuidade à construção de um corpo de conhecimentos, agora contemplando outros objetos de investigação. Esse redirecionamento se dá em consonância com a crítica mundial que o enfoque positivista havia sofrido por parte das ciências sociais. TRIVIÑOS (1987) assinala que as criticas mais contundentes e respeitáveis partiram dos neomarxistas, agrupados na Escola de Frankfurt, e de pensadores como Husserl, Mearleau-Ponty e Heidegger que constituíram as bases da fenomenologia.

A contribuição desses pensadores foi evidenciar que o pensamento positivista, com sua observância à quantificação, à objetividade e ao estabelecimento de relações entre fatos, estatisticamente significantes, encerrava a análise das realidades precisamente no ponto onde deveria iniciá-la. Estes momentos de ruptura epistemológica são fundamentais para o emergir de novas concepções cientificas a partir da descoberta do cientista que os paradigmas disponíveis não conseguem explicar um fenômeno ou um fato novo. CHAUÍ(1995) lembra que essas rupturas possibilitam à ciência que caminhe não em via linear, contínua e progressiva, mas por saltos.

Esse momento da pesquisa remeteu a questões de natureza epistemológica surgindo, então, também para a enfermagem, a necessidade de se clarear tópicos de ordem metodológica. A pesquisa qualitativa passa a se constituir para as enfermeiras num modelo alternativo para sua investigação.

No Brasil, a exemplo do que ocorreu na enfermagem norte-americana, houve um periodo em que o método científico clássico foi o único referencial para condução da pesquisa. Da primeira produção sistematizada do conhecimento de enfermagem ${ }^{1}$ até o início da década de 80 , as pesquisas realizadas pelos enfermeiros vinham contemplando

\footnotetext{
' Recursos e necessidades - Estudo realizado pela Associação Brasileira de Enfermagem, 1956 a 1958.
} 
objetos de estudo direcionados para o componente biológico do cuidado de enfermagem, análises das atividades administrativas desenvolvidas por enfermeiros nas instituições, segundo perspectivas funcionalistas, padronização e testes de técnicas e estudos de normalidade de parâmetros biológicos.

A natureza desses objetos e, fundamentalmente, a forma de visá-los, possibilitou um avanço na construção de um corpo de conhecimentos em enfermagem gerando um impulso e uma consolidação dessa forma de pesquisa.

A partir desse primeiro corpo de conhecimentos científicos e de forma interligada aos avanços da ciência, de novas incorporações na esfera tecnológica e de um descortinamento da própria concepção de ciência, novos objetos foram se mostrando aos enfermeiros como carentes de investigação. Mesmo um objeto já estudado, vai se mostrando sob outras óticas, outras perspectivas.

Vários trabalhos realizados no início da década de 80 , ao analisarem a literatura em enfermagem produzida até então no Brasil, evidenciam a influência do positivismo(ANGERAMI \& MENDES,1989; ROCHA \& SILVA,1987 e VIEIRA,1980). A partir desta década surgem investigações norteadas por outras fundamentações teóricas.

Na saúde pública, os determinantes sócio-econômicos no processo saúdedoença estavam em discussão e um dos referenciais de análise era o materialismo histórico, tendo por pressuposto que as categorias marxistas, tais como foram utilizadas para estudar o modo de produção capitalista, a saber, ideologia, classes sociais, processo de trabalho, entre outras, poderiam elucidar os problemas com os quais se deparava a prática médica. O objeto de trabalho desta prática não poderia se limitar ao corpo anátomobiológico, que deveria ser compreendido em sua dimensão social.

Alguns pesquisadores enfermeiros, em consonância com estas idéias, produzem 
as primeiras teses de doutorado e dissertações de mestrado, buscando entender a enfermagem como uma prática social.

Por outro lado, enfermeiros preocupados com as relações interpessoais no contexto hospitalar, em toda sua abrangência e considerando os co-determinantes gerados por profundas modificações decorrentes da intensificação tecnológica, se voltam para idéias que venham a contemplar a perspectiva do sujeito a quem o cuidado é prestado. Nesse sentido, emergem a linguagem, a relação dialógica, a intersubjetividade como componentes essenciais na produção de um novo conhecimento. A fenomenologia se apresenta, então, como um referencial para fundamentar investigações pertinentes ao cotidiano de trabalho do enfermeiro quando se fazem presentes situações de dor, sofrimento, perdas, relações empáticas, de rejeição, de conflito.

Dissertações de mestrado e teses de doutorado, a partir da década de oitenta, são realizadas segundo o referencial metodológico da fenomenologia, trazendo a dimensão existencial do sujeito a quem o cuidado é prestado.

Vale ressaltar que, durante a década de oitenta, o país passa por profundas tranformações marcadas de um lado por uma crise econômica intensa e prolongada e de outro pela superação de um longo período autoritário, restaurando-se a ordem democrática. A organização do setor saúde é intensamente discutida, questionando-se o modelo previdenciário, incompativel com as demandas da população, sendo colocadas em pauta questões como a extensão de cobertura, a regionalização, a participação popular, a cidadania, em busca de novas formas de organização da assistência. Os fundamentos do marxismo se apresentam pertinentes enquanto referencial para a investigação.

Segundo CHAUÍ(1995), os paradígmas filosóficos da fenomenologia permitiram 
a definição e a delimitação dos objetos das ciências humanas e os do marxismo permitiram compreender que os fatos humanos são historicamente determinados e que a historicidade possibilita a sua interpretação e o conhecimento de suas leis.

Inserindo-se em um movimento que reconhece a não neutralidade da ciência, a enfermagem vai incorporando novas temáticas como objeto de estudo, entre elas, as questões de genêro e saúde da mulher, saúde e estilo de vida, promoção em saúde, comunicação em enfermagem, saúde e cidadania, recursos humanos, saúde do trabalhador, o trabalhador em saúde e suas condições de trabalho, a desinstitucionalização do paciente psiquiátrico, o hospital como instrumento diagnóstico e terapêutico e também como cenário de dominação e subordinação, a puericultura como norma disciplinadora de comportamentos, a historicidade do trabalho das enfermeiras, as dificeis relações da equipe de saúde em situações de doença grave e morte. Muitos pesquisadores voltamse para a compreensão do papel do enfermeiro nas instituições, suas atividades em relação ao conjunto da equipe multiprofissional e a adequação entre o ensino superior de enfermagem e o mercado de trabalho.

Epistemologicamente, então, novos horizontes se abrem para a geração do conhecimento em enfermagem e esse novo conhecimento possibilitou aos enfermeiros extrapolar o modelo biológico e propor o cuidado de enfermagem para além da técnica, para além da quantificação e da observação de sinais e sintomas, para uma transcendência do aspecto ôntico do cuidado para o ontológico.

Os resultados dessas investigações permitiram ainda aos enfermeiros um diálogo acadêmico interdisciplinar, tornando possivel, assim, uma relação intersubjetiva com profissionais de áreas afins, na medida em que a subjetividade dos enfermeiros, trabalhada metodologicamente, se objetiva no diálogo acadêmico, na elaboração de propostas, na configuração de diretrizes para o setor saúde. 
Para o enfermeiro, enquanto categoria profissional, o novo conhecimento possibilitou a compreensão de sua inserção no processo de trabalho em saúde e as consequências das relações de poder, dominação, subordinação, inerentes a uma sociedade dividida em classes sociais.

Em relação à clientela, ou seja, o homem a quem cuidamos, sob a ótica individual ou coletiva, os enfermeiros puderam visá-la, não mais em uma perspectiva universal e abstrata, com necessidades biopsicosociais inespecificas, mas diferenciada de acordo com suas condições de existência e determinadas por sua inserção no modo de produção.

\section{REFLEXÕES SOBRE A PESQUISA QUALITATIVA EM ENFERMAGEM}

Pouco mais de uma década se passou desde que os enfermeiros brasileiros puderam se apropriar destes referenciais metodológicos, instrumentalizando-se para suas pesquisas. Assim, uma reflexão sobre essa apropriação e suas implicações para o conhecimento que vem sendo produzido nos parece oportuna, ainda que seja realizada de forma embrionária. Reflexão entendida, segundo MEARLEAU-PONTY(1973), não como observação de um fato mas como esforço para compreender. Não se trata, diz o filósofo, da passividade de um sujeito que contempla sua vivência e sim o esforço de um sujeito que apreende a significação de seu trabalho.

Um primeiro tópico dessa reflexão diz respeito ao que se entende por pesquisa qualitativa. MARTINS \& BICUDO(1989), nomes brasileiros respeitáveis nessa forma de pesquisar, lembram que a pesquisa qualitativa é concebida como sendo um empreendimento mais abrangente e multidimensional, havendo uma variedade de procedimentos metodológicos e de concepções que estão sendo desenvolvidos por vários pesquisadores para contemplar os aspectos qualitativos dos fenômenos pesquisados.

Para esses autores, as diferenças metodológicas encontradas nas modalidades 
de pesquisa qualitativa resultam das diferenças existentes nas formas de delimitar o campo da pesquisa e da própria natureza dos fenômenos estudados. Ressaltam ainda que um aspecto importante que contribui para a existência dessas diferenças é o concernente à idéia ou tipo de conhecimento que se deseja obter e que essas diferenças de enfoque são intimamente ligadas às distintas trajetórias na busca de bases que fundamentem respostas às questões de método.

Cabe mencionar que um aspecto que tem gerado alguns equívocos diz respeito ao uso de termos como pesquisa qualitativa, etnográfica, fenomenológica, participante, estudo de campo, muitas vezes empregados indevidamente como equivalentes. Efetivamente há diferentes modalidades de pesquisa qualitativa. Cada uma guarda uma relação impar com seus pressupostos, métodos, papel do observador, técnicas de coleta de dados e o delineamento mesmo da pesquisa. Os diferentes caminhos metodológicos precisam ser percorridos com fiel observância aos pressupostos filosóficos que os norteiam. É neste ato de vigilância constante que reside o rigor científico. $O$ conhecimento destes pressupostos, implícitos no referencial téorico e explícitos no diálogo que cada trabalho, em particular, realiza ao problematizar seu tema de investigação, possibilita ao pesquisador a criação de diferentes delineamentos de investigação, numa liberdade criadora responsável por resguardar a coerência com os pilares filosóficos.

Cabe mencionar ainda que as modalidades de pesquisa qualitativa guardam intima relação com um vocabulário que thes é próprio. Os vocábulos são conceitos que expressam a visão de mundo contida nos referenciais. A apropriação de uma linguagem revela a aderência do pesquisador ao referencial que selecionou para fundamentar sua investigação ou sua incorência ao transitar entre conceitos que têm significados inadequados no conjunto dos argumentos que está defendendo. .

MARTINS(1989) alerta que o tratamento da experiência humana e de seus 
significados precisa ser conduzido por métodos adequados, consistentes e pertinentes. É preciso, diz esse pesquisador, assegurar que um dialógo entre enfoque, método e conteúdo seja consistente e, portanto, que mantenha um rigor.

TRIVIÑOS(1987), analisando a investigação educacional no Brasil, constata que a investigação que se realiza nas universidades não vem contribuindo para as desejáveis transformações no ensino nacional e atribui este fato à confusão, à mistura, ao ecletismo presentes em grande parte das pesquisas. Explicita que o investigador pode usar em seus trabalhos conceitos que tenham as suas raízes em ideologias divergentes, inclusive opostas, mas por coerência e disciplina, deve ligar a apropriação de qualquer idéia à sua concepção do mundo, em primeiro lugar, e, em seguida, inserir essa noção no quadro teórico especifico que the serve de apoio para o estudo dos fenômenos sociais. Identifica uma indisciplina, caracterizada por uma mistura de correntes de pensamento, citações avulsas, fora de contexto. A indisciplina intelectual revela um processo de formação acadêmica unilateral que nega a pretensão do autor de demonstrar uma visão pluralista. Esta formação sonega uma ampla faixa de idéias e impede o desenvolvimento do espírito crítico. Revela ainda a dependência cultural em que vivemos, da qual é difícil fugir, porque o meio exige falar a linguagem do centro produtor e propagador da cultura, ciência e técnica.

Esta análise sobre a produção de conhecimentos em educação no Brasil pode ser remetida à outras áreas, incluindo a enfermagem, considerando que parte do conhecimento que vem sendo produzido está carecendo da disciplina identificada por TRIVIÑOS(1987), na medida em que se apresenta com o mesmo ecletismo.

Por disciplina entendemos um estudo sistemático das bases filosóficas do conhecimento científico, que possibilite ao investigador conhecer o quadro de referências básicas onde situam-se as teorias e pressupostos da pesquisa. O problema de 
investigação e o delineamento do objeto a ser pesquisado podem, então, serem vistos com clareza. O levantamento bibliográfico sobre a temática escolhida para estudo ou a exploração da região de inquérito levam a um diálogo entre o investigador e seu referencial teórico. A partir daí, a escolha do método, técnicas e estratégias de investigação devem, necessariamente, ter coerência interna.

No que se refere ao campo de conhecimentos da área enfermagem, seus fundamentos situam-se em biologia, ciências humanas e sociais. Todavia, a fundamentação que estas ciências pode dar não está pronta, isto é, não pode ser utilizada de forma prescritiva na prática cotidiana da assistência e do cuidar. Nesse sentido, a investigação em enfermagem precisa percorrer um caminho para focalizar seus problemas específicos, elaborar os dados empíricos à luz de referenciais teóricos, reconstruindoos, de forma a possibilitar uma estrutura de conhecimentos que fundamente sua prática.

Estes conhecimentos, revestidos de uma lógica interna, poderão fornecer respostas às indagações que se colocam, possibilitando as transformações desejadas na assistência e na pesquisa.

\section{REFERÊNCIAS BIBLIOGRÁFICAS}

ALMEIDA, M. C. P. \& ROCHA, J. S. Y. O saber de enfermagem e sua dimensão prática. São Paulo, Cortez, 1986.

ANGERAMI, E. L. S. \& MENDES, I. A. C. O saber, a saúde e a investigação em enfermagem. Rev. Gaúcha Enf., Porto Alegre, 10:28-33, 1989.

CHAUİ,M. Convite à filosofia. São Paulo, Àtica, 1995.

CUSHING, A. Historical epistemological perspectives on research and nursing. J. Adv. Nur., 20:406-11, 1994. 
MERLEAU-PONTY, M. Ciências do homem e fenomenologia. São Paulo, Saraiva, 1973.

MARTINS, J. \& BICUDO, M. A. V. A pesquisa qualitativa em psicologia : fundamentos e recursos básicos. São Paulo, EDUC/Moraes, 1989.

OMERY, A. Phenomenology: a method for nursing research. Ad. Nur. Sci., 52:49-63, 1983.

RAY, M. A. A philosophical method to study nursing. In : Leininger, M. M., Qualitative research methods in nursing. New York, Grune \& Stratton, 1985.

ROCHA, S. M. M. \& SILVA, G. B. Linhas filosóficas e ideológicas na pesquisa em enfermagem. Rev. Bras. de Enf., 40:214-21,1987.

SAUER, J.L. Using a phenomenological research method to study nursing phenomena. In : Leininger, M. M., Qualitative research methods in nursing. New York, Grune \& Stratton, 1985.

TRIVIÑOS, A.N.S. Introdução à pesquisa em ciências sociais: a pesquisa qualitativa em educação. São Paulo, Atlas, 1987.

VIEIRA, T. T. Produção científica em enfermagem no Brasil : 1960 - 1979. Salvador, 1980 [Tese de Livre-Docência - Escola de Enfermagem da Universidade Federal da Bahia].

Summary: The article aims at making some considerations on nursing research in relation to this theoretical framework and methodological pathways. For that purpose the authors recapture the moment when nursing goes through a redirecting of the classical investigation method to new epistemological horizons for knowledge generation. The authors also discuss issues related to the internal coherence of qualitative research and the observance of philosophical premises emphasising the importance of the production of knowledge in response to queries on the assisting and caring in nursing.

Key words: Nursing research; qualitative research; caring in nursing; theorical and methodological aproaches; epistemology 